\title{
Oral adrenergic agents produced Ventricular fibrillation and QT prolongation in an elderly patient carrying an $R Y R 2$ variant.
}

\author{
Kanae Hasegawa ${ }^{1}$, Kentaro Ishida ${ }^{2}$, Shinsuke Miyazaki $^{3}$, Seiko Ohno $^{4}$, Minoru Horie ${ }^{5}$, \\ Hiroyasu Uzui ${ }^{2}$, and Hiroshi Tada ${ }^{1}$ \\ ${ }^{1}$ University of Fukui \\ ${ }^{2}$ Faculty of Medical Sciences, University of Fukui \\ ${ }^{3}$ University of Fukui Faculty of Medical Sciences \\ ${ }^{4} \mathrm{NCVC}$ \\ ${ }^{5}$ Shiga University of Medical Science
}

May 3, 2021

\begin{abstract}
Mutant cardiac ryanodine receptor channels (RyR2) are "leaky," and spontaneous Ca2+ release through these channels causes delayed afterdepolarizations that can deteriorate into ventricular fibrillation (VF). RYR2 is a causative gene of type 1 catecholaminergic polymorphic ventricular tachycardia (CPVT). Some patients carrying RYR2 mutations in CPVT exhibit QT prolongation and are initially diagnosed with long QT syndrome. However, none have been reported to cause drug-induced VF in patients with RYR2 variants. We describe the first case of an elderly woman with drug-induced QT prolongation and VF who carried a novel RYR2variant but no other mutations related to long QT syndrome.
\end{abstract}

\section{Hosted file}

Hasegawa diVF RYR2 JCE FINAL3.pdf available at https://authorea.com/users/411642/articles/ 520599-oral-adrenergic-agents-produced-ventricular-fibrillation-and-qt-prolongation-inan-elderly-patient-carrying-an-ryr2-variant 


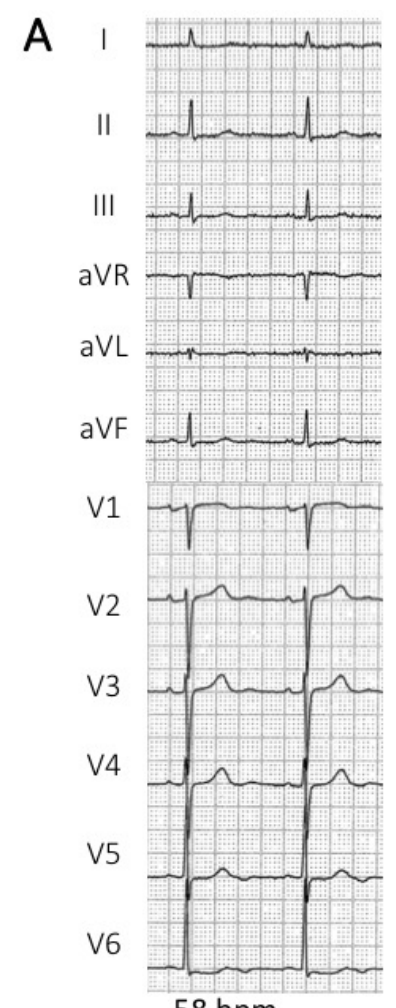

B ।

II

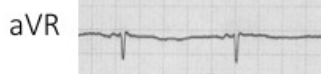

$\mathrm{aVL}$

aVF

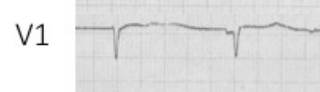

V2

V3

V4

V5

V6

$58 \mathrm{bpm}$ $\mathrm{QT} / \mathrm{QTc}=438 / 432 \mathrm{~ms}$
II
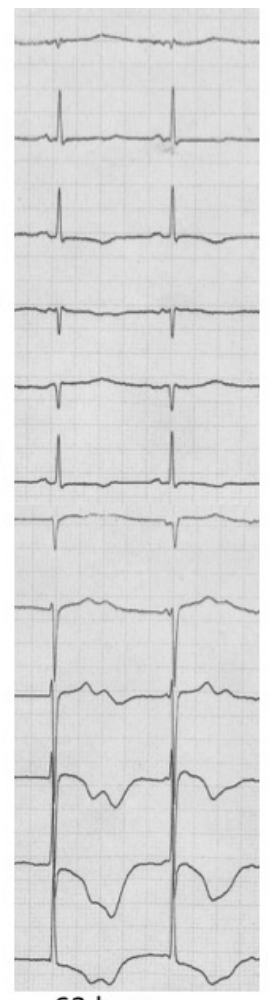

$63 \mathrm{bpm}$ $\mathrm{QT} / \mathrm{QTC}=600 / 614 \mathrm{~ms}$

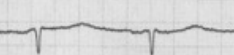

C I

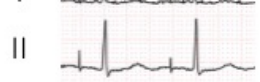

III
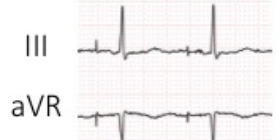

aVt

V1 rrom

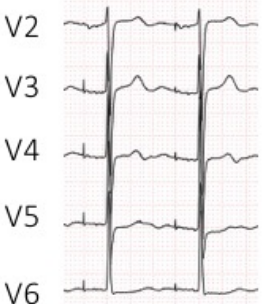
$1 \mathrm{mV}$

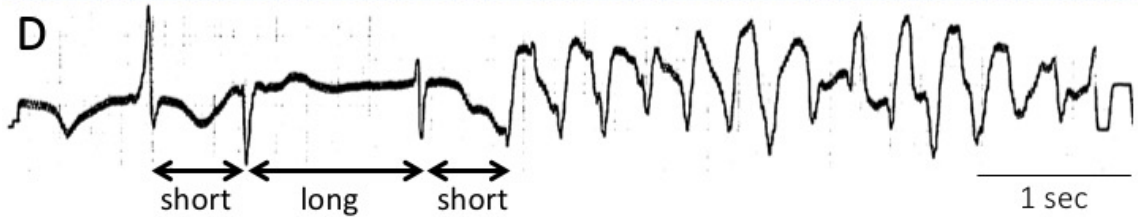



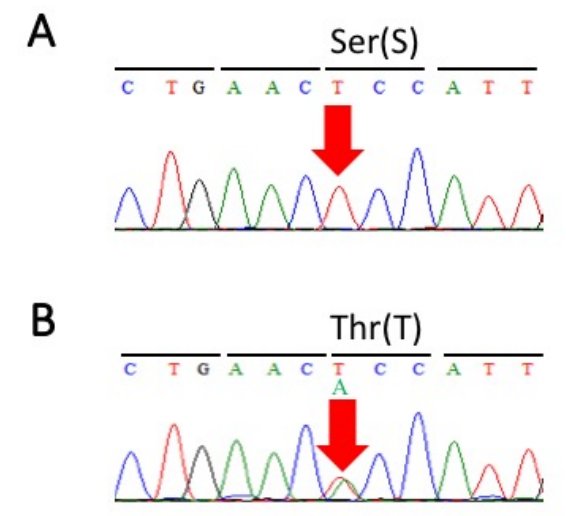